\title{
Comparison of Intravenous Dexmedetomidine versus Labetalol for Their Effectiveness in Suppression of Haemodynamic Response during Extubation
}

\author{
Parth M. Shah ${ }^{1}$, Divya Kheskani ${ }^{2}$ \\ ${ }^{1}$ Associate Professor, Dr. M.K. Shah Medical College, Hospital \& Research Centre, Shyanmal, Satellite, \\ Ahmedabad - 380015, Gujarat. \\ ${ }^{2}$ Assistant Professor, GCS Medical College, Hospital \& Research Centre, Shyanmal, Satellite, \\ Ahmedabad - 380015, Gujarat.
}

Corresponding Author: Divya Kheskani

\begin{abstract}
Background: Tracheal extubation causes autonomic nervous system disturbances which causes tachycardia, hypertension which are harmful in susceptible patients.so we conducted a study between iv Dexmedetomidine and iv Labetalol to assess their effectiveness in decreasing haemodynamic disturbances during extubation.
\end{abstract}

Materials and Methods: we included 100 participants of age of 18-55 yrs with ASA grading I \& II and divided them into 2 groups. Group D was given injection Dexmedetomidine $0.6 \mathrm{mcg} / \mathrm{kg}$ iv and Group L was given injection Labetalol $0.25 \mathrm{mg} / \mathrm{kg}$ body weight. We recorded Heart rate, systolic and diastolic blood pressure at baseline, 2,5,8 minutes post drug injection, at extubation and 1,3,5,8,10 and 15 minutes after extubation.

Results: Group D had better decreased heart rate, systolic and diastolic blood pressure at the time of extubation, and also 15 minutes post extubation in comparison to Group L.

Conclusion: Injection Dexmedetomidine $0.6 \mu \mathrm{g} / \mathrm{kg}$ has showed a better attenuating effect on sympathoadrenal system during extubation than injection Labetalol $0.25 \mathrm{mg} / \mathrm{kg}$

Keywords: Dexmedetomidine, labetalol, extubation, hemodynamics

\section{INTRODUCTION}

Endotracheal intubation and extubation are associated with various cardiovascular and airway responses that lead to hemodynamic instability due to sympathetic discharge caused by epipharyngeal and laryngeal stimulation. $[1,2]$

All these transitory responses might lead to unpredictable and hazardous effects in patient with pre-existing co-morbidities. [3]

Different strategies have been
employed to control emergence hypertension such as extubation in a deep plane of anesthesia, drugs as lidocaine, labetalol, esmolol, and intravenous opiates such as morphine, fentanyl. [4]

Preemptive therapy is another such effort used now a days to avoid occurrence of such effects Dexmedetomidine is a selective $\alpha 2$ agonist that provides sedation, hypnosis, analgesia and sympatholysis. It maintains intraoperative haemodynamics by decreasing levels of catecholamines during surgery [5]

Labetalol is a unique antihypertensive adrenergic antagonist having an effect on both selective $\alpha 1$ and nonselective $\beta 1$ and $\beta 2$, with rapid onset of action and reaches its peak effect at 515 min after i.v. injection [6,7] 
This study was planned primarily to compare iv Dexmedetomidine $0.6 \mu \mathrm{g} / \mathrm{kg}$ and Labetalol0.25mg/kg in suppression of sympathoadrenal response to evaluate haemodynamic responses at extubation.

\section{MATERIAL AND METHODS}

On approval of institutional ethics committee and written informed consent from each patient This prospective, randomized, controlled study was conducted.100 patients included in the study were of age 18-50 years of either sex, belonging to ASA grade I-II posted for elective surgery of duration less than two hours under general anaesthesia with endotracheal intubation. Patients excluded were those with known hypersensitivity to study drugs, pregnant females, patients with cardiovascular, respiratory, hepatic or renal diseases, patients on $\beta$ blockers, patients with anticipated difficult intubation, heart blocks, bradycardia (heart rate $<60 \mathrm{bpm}$ ) and those patients in whom intubation was attempted for more than 30 seconds.

Patients were assessed for pre anaesthesia checkup, all required investigations were done and were instructed to maintain nil by mouth for 8 hours.

The patients were randomly allocated with the help of computer generated coded envelops based on study drugs into two groups of 50 each as per protocol given below:

Group D received injection Dexmedetomidine $0.6 \mu \mathrm{g} / \mathrm{kg}$ body weight diluted upto $10 \mathrm{ml}$ with normal saline intravenously over 10 minutes using a syringe pump before extubation.

Group L - received injection Labetalol $0.25 \mathrm{mg} / \mathrm{kg}$ body weight diluted upto $10 \mathrm{ml}$ with normal saline given intravenously over 10 minutes using a syringe pump before extubation.

In the pre-operative room, under all aseptic and antiseptic precautions a peripheral intravenous line was secured by $18 \mathrm{G}$ canula. The patients were then preloaded with $500 \mathrm{ml}$ ringer lactate solution.

On shifting to the operating room, all patients were monitored for baseline vital parameters like non-invasive blood pressure, heart rate (HR), pulse oximeter (SpO2) and electrocardiograph (ECG). The patients were premedicated with glycopyrrolate $5 \mathrm{mcg} / \mathrm{kg}$, ondansetron $0.1 \mathrm{mg} / \mathrm{kg}$ and fentanyl $1 \mathrm{mcg} / \mathrm{kg}$ intravenously and were preoxygenated with $100 \%$ oxygen.

Anaesthesia was induced with propofol $2 \mathrm{mg} / \mathrm{kg}$ followed by suxamethonium $1.5 \mathrm{mg} / \mathrm{kg}$. Ventilation of lungs was manually assisted till muscles were relaxed satisfactorily. Then laryngoscopy was carried out and patient's airway was secured with an endotracheal tube of appropriate size and was fixed after checking bilateral equal air entry.

Anaesthesia was maintained with oxygen, nitrous oxide, sevoflurane with intermittent dose of injection atracurium.

Group D received injection Dexmedetomidine $0.6 \mu \mathrm{g} / \mathrm{kg}$ diluted upto $10 \mathrm{ml}$ with normal saline intravenously over 10 minutes using a syringe pump before extubation and Group L - received injection Labetalol $0.25 \mathrm{mg} / \mathrm{kg}$ diluted upto $10 \mathrm{ml}$ with normal saline given intravenously over 10 minutes before extubation.

At the end of the procedure, neuromuscular blockade was reversed with Inj neostigmine $0.05 \mathrm{mg} / \mathrm{kg}$ body weight and Inj glycopyrrolate $0.01 \mathrm{mg} / \mathrm{kg}$ body weight.

Haemodynamic parameters such as heart rate, systolic and diastolic blood pressure were recorded

- at baseline

- 2, 5, 8 minutes after drug infusion

- at the time of extubation

- at $1,3,5,8,10$ and 15 minutes postextubation.

\section{STATISTICAL METHOD}

Demographic data of the patients were expressed as mean \pm standard deviation. The statistical data were analysed by mean, standard deviation and $\mathrm{p}$ values 
Parth M. Shah et.al. Comparison of intravenous dexmedetomidine versus labetalol for their effectiveness in suppression of haemodynamic response during extubation.

were calculated by using SPSS trial RESULT software version 26.

Demographic variables among 2 groups were comparable with respect to age, sex, height, weight and duration of surgery.

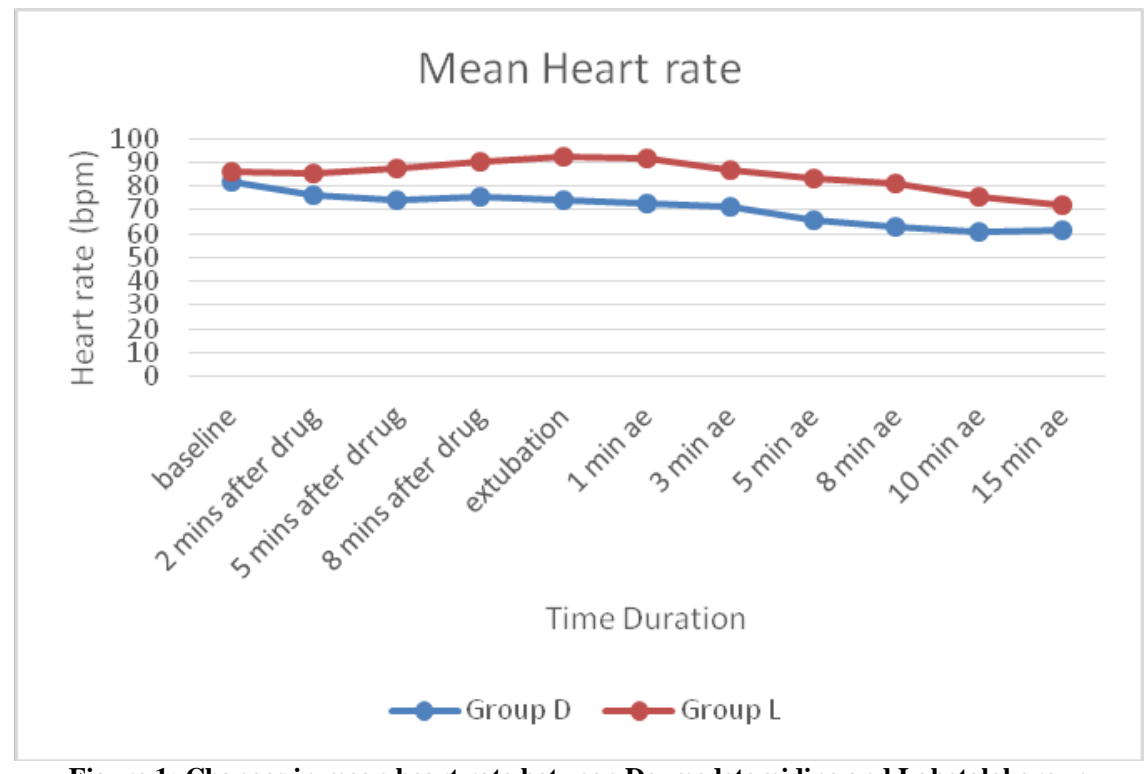

Figure 1: Changes in mean heart rate between Dexmedetomidine and Labetalol group

The baseline mean heart rate in patients of both groups was comparable and statistically insignificant

In both groups, there was decrease in mean heart rate after drug infusion and at 1 , 3, 5, 8, 10 and 15 mins post extubation (Figure 1)

However, the decrease in mean heart rate was more significant in group $\mathrm{D}$ at 2, 5, 8 mins after drug administration, at extubation and 1, 3, 5, 8, 1015 mins post extubation as compared to group $\mathrm{L}$

At extubation there was decrease in mean heart rate by $8 \mathrm{bpm}$ from baseline in group $\mathrm{D}$ and increase by $6 \mathrm{bpm}$ in group $\mathrm{L}$ from baseline. The changes were statistically significant $\mathrm{p}$ value $<0.0001$ as compared to group L(figure 1)

Mean heart rate was below baseline values even at $15^{\text {th }}$ minutes post extubation in both groups.

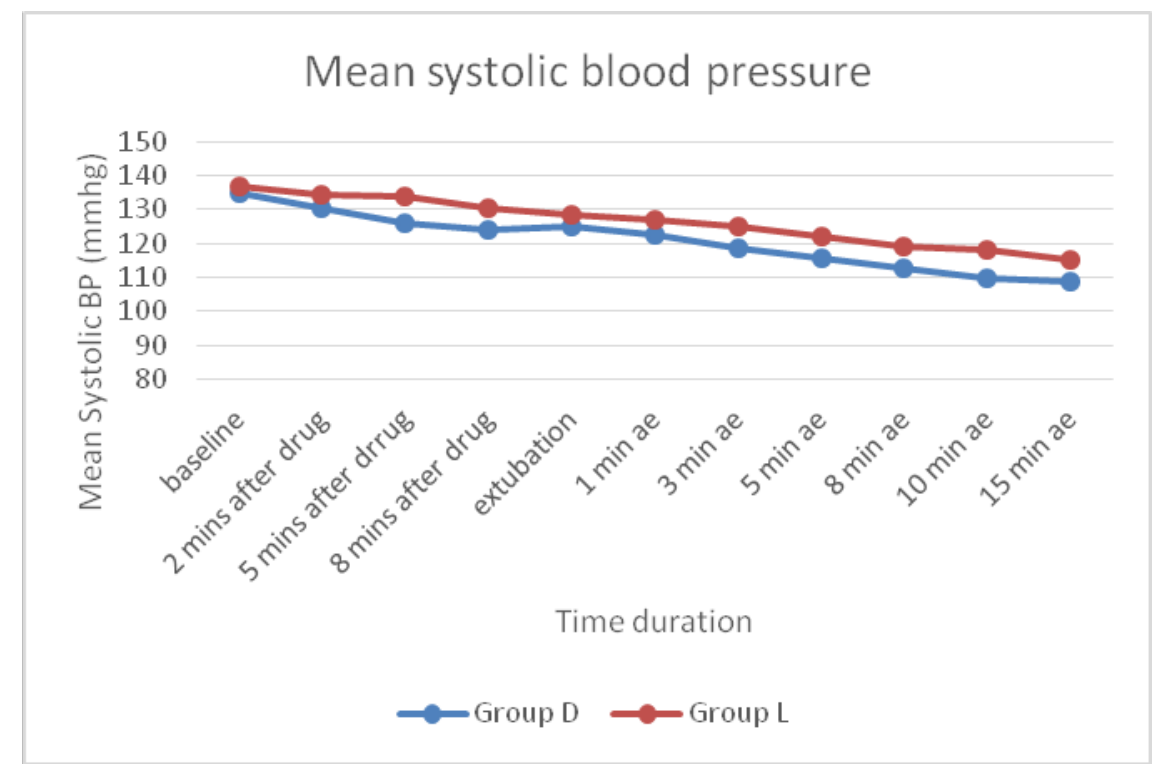

Figure 2: Changes in mean systolic blood pressure between Dexmedetomidine and Labetalol group 
Parth M. Shah et.al. Comparison of intravenous dexmedetomidine versus labetalol for their effectiveness in suppression of haemodynamic response during extubation.

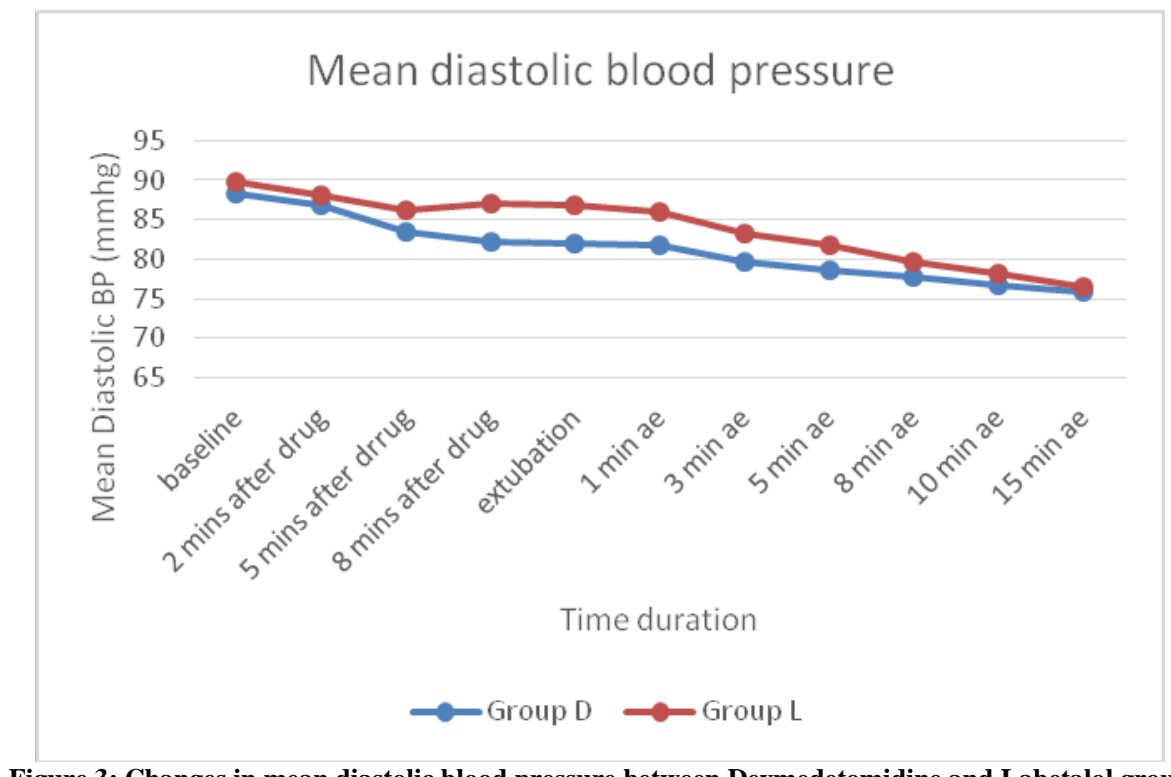

Figure 3: Changes in mean diastolic blood pressure between Dexmedetomidine and Labetalol group

The baseline mean systolic and diastolic blood pressure in patients of both groups was comparable and statistically insignificant

There was decrease in mean systolic and diastolic blood pressure in both groups after administration of drugs. Group D showed a greater decrease in mean systolic and diastolic blood pressure at 2, 5, 8 mins after drug administration, at extubation and until 15 min post extubation as compared to baseline parameters. (figure 2,3)

At extubation in group $\mathrm{D}$ the decrease in mean systolic and diastolic blood pressure was 9 and $6 \mathrm{~mm}$ hg from baseline respectively with $\mathrm{p}$ value $<0.0001$ statistically when Compared to group L where the decrease in mean systolic and diastolic blood pressure was 8 and $3 \mathrm{mmhg}$ from baseline respectively.

The mean systolic as well as diastolic blood pressure remained below the baseline parameters until 15 mins post extubation also. (figure 2,3)

\section{DISCUSSION}

Various theories have explained sudden increase in $\mathrm{HR}$ and $\mathrm{BP}$ during extubation such as a rise in catecholamine, airway irritation owing to suction, intense pain from surgical wounds and emergence. [8]
This evokes noxious stress responses and causes disturbance in hemodynamic parameters like tachycardia, hypertension, change in heart rhythm and evokes coughing, bronchospasm, raised intraocular, intracranial pressure and thus hazardous consequences in vulnerable patients [9]

Dexmedetomidine, an alpha-2 adrenergic agonist possesses properties of sympatholysis, titratable sedation without respiratory depression, analgesia, benefit of reduced dosage of opioids. [10]

It is a small molecule possessing an imidazole ring with distribution half-life of 6-8 minutes on intravenous administration [11,12] it possesses eight times more affinity for alpha-2 adrenoceptors as compared to clonidine, Hence a preferred agent as a full alpha-2 adrenoceptor agonist. [13] Activation of these presynaptic alpha 2 receptors inhibits release of norepinephrine and terminates transmission of noxious stimuli. Thus, it attenuates sympathoadrenal response by changes in haemodynamic parameters -decrease in heart rate and blood pressure by inhibiting the sympathetic activity through activation of postsynaptic alpha-2 receptors [14]

Labetalol, an antihypertensive drug used widely as an alpha-1, nonselective beta- 1 and beta-2 adrenergic antagonist. $\mathrm{R}$ isomer of labetalol has potent vasodilatory 
effect with intrinsic sympathomimetic effect on beta adrenergic receptors. [15]

On intravenous administration it reaches peak effect by 5 -15minutes and attenuates sympathoadrenal response by decreasing heart rate by blocking beta adrenergic receptor and blood pressure by blocking alpha 1 adrenergic receptors. [16,17]

As very few researchers have conducted study comparing role of dexmedetomidine and labetalol for suppression of sympathoadrenal stress response to extubation we conducted a study their effect on hemodynamic parameters during extubation.

Rapid Intravenous administration of dexmedetomidine leads to transient increase in blood pressure and decrease in heart rate due to stimulation of peripheral alpha-2B adrenoceptor.

To overcome this hurdle, we administered dexmedetomidine $0.6 \mu \mathrm{g} / \mathrm{kg}$ diluted upto $10 \mathrm{ml}$ with normal saline slowly using syringe pump.

Considering time of peak effect of labetalol, we administered intravenous labetalol $0.25 \mathrm{mg} / \mathrm{kg}$ over 10 mins diluted in $10 \mathrm{ml}$ normal saline with syringe pump.

Our study results on analysis show at extubation Dexmedetomidine group showed decrease in mean heartrate by 8 bpm, mean systolic by 9 mmhg and diastolic blood pressure by 6 mmhg In Group labetalol at extubation, the mean heart rate was increased by $6 \mathrm{bpm}$, and mean systolic and diastolic blood pressure was decreased by 8 mmhg and 3 mmhg respectively. These changes were statistically highly significant as compared to baseline (p value $<0.0001$ )

In Both groups the heart rate, systolic blood pressure, diastolic blood pressure remained below the baseline within permissible limits 15 mins post extubation.

But the overall hemodynamic stability of dexmedetomidine was better than labetalol group at various time intervals and hence Dexmedetomidine maintains stable hemodynamic parameters as compared to Labetalol.
Sindhu S, V Y Srinivas et al conducted a study entitled "to study the effect of iv dexmedetomidine versus iv labetalol for the suppression of sympatho adrenal response to extubation" where they included 60 patients and concluded that administration of injection dexmedetomidine $0.6 \mu \mathrm{g} / \mathrm{kg}$ resulted in more hemodynamic stable parameters as compared to labetalol administered $0.25 \mathrm{mg} / \mathrm{kg}$ iv during extubation. At extubation in group $\mathrm{D}$ the decrease in heart rate, systolic blood pressure, diastolic blood pressure in their study was $3 \mathrm{bpm}, 13 \mathrm{~mm}$ hg and $10 \mathrm{mmhg}$ respectively. In labetalol group the increase in heart rate was $9 \mathrm{bpm}$, decrease in systolic and diastolic blood pressure was $5 \mathrm{~mm} \mathrm{hg}$ and $3 \mathrm{mmhg}$ respectively [18]

The above study results are quite similar to ours and thus strengthen our findings.

In our study even though mean heart rate, systolic and diastolic blood pressure remained below the baseline value even at 15 minutes postextubation in both groups.

We conclude that Dexmedetomidine was better in maintaining stable haemodynamic parameters compared to Labetalol at various time intervals that were monitored.

Kewalramani et al carried out a study entitled "Comparison of labetalol versus dexmedetomidine to assess the haemodynamic responses to laryngoscopy and intubation during induction of general anaesthesia "and compared Dexmedetomidine $0.5 \mu \mathrm{g} / \mathrm{kg}$ with labetalol $0.25 \mathrm{mg} / \mathrm{kg}$ iv for supressing hemodynamic responses at intubation and extubation stated that dexmedetomidine has better attenuation than labetalol. At extubation dexmedetomidine heart rate was increased 2 bpm whereas in labetalol increase was 6bpm. [19]

The research conducted by D Single et al included borderline hypertensive patients undergoing laparoscopic cholecystectomy stated that labetalol group showed higher systolic blood pressure 
$(128.0 \pm 13.866$ vs $123.2 \pm 10.672)$ and diastolic blood pressure $(79.2 \pm 14.153$ vs 73.1 \pm 9.683 ) compared to Dexmedetomidine group. This study results strengthen our result analysis. [20]

Kotak $\mathrm{N}$ et al compared Dexmedetomidine with esmolol and proved that dexmedetomidine showed more stable hemodynamic parameters at extubation. [21]

Many other studies have also been carried out comparing Dexmedetomidine with other agents and have similar conclusion.

\section{CONCLUSION}

In a nutshell, intravenous Dexmedetomidine at dose of $0.6 \mathrm{microgram} / \mathrm{kg}$ is a better agent than labetalol $\quad 0.25 \mathrm{mg} / \mathrm{kg}$ in supresses sympathetic response to tracheal extubation.

\section{Acknowledgement: None}

\section{Conflict of Interest: None}

\section{Source of Funding: None}

\section{Ethical Approval: Approved}

\section{REFERENCES}

1. Nishina K, Mikawa K, Maekawa N, Obara $\mathrm{H}$. Attenuation of cardiovascular responses to tracheal extubation with diltiazem. Anesth Analg. 1995;80:121722. [PubMed] [Google Scholar]

2. Fujii Y, Saitoh Y, Takahashi S, Toyooka H. Combined diltiazem and lidocaine reduces cardiovascular responses to tracheal extubation and anesthesia emergence in hypertensive patients. Can J Anaesth. 1999;46:952-

6. [PubMed] [Google Scholar]

3. Mikawa K, Nishina K, Maekawa N, Obara $\mathrm{H}$. Attenuation of cardiovascular responses to tracheal extubation: Verapamil versus diltiazem. Anesth Analg. 1996;82:120510. [PubMed] [Google Scholar]

4. Hartley M, Vaughan RS. Problems associated with tracheal extubation. $\mathrm{Br} \mathrm{J}$ Anaesth 1993; 71:561-568.
5. Babita, Singh B, Saiyed A, Meena R, Verma I, Vyas CK. A comparative study of labetalol and fentanyl on the sympathomimetic response to laryngoscopy and intubation in vascular surgeries. Karnataka Anaesth J 2015;1:64-68.

6. Kanto J, Allonen $\mathrm{H}$, Kleimola $\mathrm{T}$. Pharmacokinetics of labetalol in healthy volunteers. Int $\mathrm{J}$ Clin Pharmacol Ther Toxicol 1981; 19:41-44.

7. Stoelting RK, Hillier SC. Pharmacology \& physiology in anesthetic practice. In: Robert KS, Simon CH, editors. Handbook of pharmacology and physiology in anesthetic practice. 2nd ed. Philadelphia, USA: Lippincott Williams \& Wilkins 2006. 347. 87-342.

8. Mikawa K, Maekawa N, Obara H. responses to tracheal extubation with diltiazem. Anesth Analg 1995; 80: 12171222.

9. Rath A, Jayanthi A, Yadav G. To evaluate and compare the effectiveness of dexmedetomidine and lidocaine on attenuation of hemodynamic responses and airway reflexes during extubation. J Evid Based Med Healthc. 2018;5(30):2209-13.

10. Vora K, Shah V, Parikh G, Baranda U, Modi M, Butala B. The effects of dexmedetomidine on attenuation of hemodynamic changes and their effects as adjuvant in anesthesia during laparoscopic surgeries. Saudi J Anaesth. 2015;9(4):38692

11. Paranjpe J. Dexmedetomidine: Expanding role in anesthesia. Med JDY Patil Univ. 2013;6(1):5-13.

12. Maze M, Tranquili W. Alpha 2adrenoceptor agonists: Defining the role in clinical anaesthesia. Anesthesiol. 1991;74:581-605.

13. Shehabi Y, Botha JA, Ernest D, Freebairn RC, Reade M, Roberts BL. Clinical application, the use of dexmedetomidine in intensive care sedation. Crit Care Shock. 2010;13:40-50.

14. Gertler R, Brown HC, Mitchell DH, Silvius EN. Dexmedetomidine: A Novel SedativeAnalgesic Agent. Bayl Univ Med Cent. 2001;14(1):13-21

15. Ebadi M. Desk reference of clinical pharmacology. Boca Raton, USA:CRC Press; 2007.

16. MacCarthy EP, Bloomfield SS. Labetalol: a review of its pharmacology, 
Parth M. Shah et.al. Comparison of intravenous dexmedetomidine versus labetalol for their effectiveness in suppression of haemodynamic response during extubation.

pharmacokinetics, clinical uses and adverse effects. Pharmacotherapy: J Human Pharmacol Drug Ther. 1983;3(4):193-217.

17. Stoelting RK, Hillier SC. Pharmacology and physiology in anesthetic practice. In: Handbook of Pharmacology and Physiology in Anesthetic Practice. vol. 347. Lippincott Williams and Wilkins; 2006. p. 87-342.

18. Sindhu S and Srinivas. To study the effect of iv dexmedetomidine versus iv labetalol for the suppression of sympathoadrenal response to extubation: Indian Journal of Clinical Anaesthesia 2020;7(2):198-202

19. Kewalramani A, Partani S, Sharma NP, Sharma V. Comparison of labetalol versus dexmedetomidine to assess the haemodynamic responses to laryngoscopy and intubation during induction of general anaesthesia - a prospective, randomized, controlled study. Indian JClin Anaesth. 2016;3(4):512-9.20.
20. Singla D, Parashar A, Pandey V, Mangla M. Comparative evaluation of dexmedetomidine and labetalol for attenuating hemodynamic stress responses during laparoscopic cholecystectomy in patients. Rev Esp Anestesiol Reanim. 2019;66(4):181-8

21. Desai P, Kotak N, Mamde R. Prospective randomized comparative trial of dexmedetomidine versus esmolol for attenuation of extubation response. Med J DY Patil Vidyapeeth. 2019;12(2):131-5

How to cite this article: Shah PM, Kheskani D. Comparison of intravenous dexmedetomidine versus labetalol for their effectiveness in suppression of haemodynamic response during extubation. International Journal of Research and Review. 2021; 8(11): 286-292. DOI: https://doi.org/10.52403/ijrr.20211137 